\title{
Being More than You Can Be Enhancement of Warfighters and the Law of Armed Conflict
}

\author{
Rain Liivoja
}

Technologically advanced armed forces have begun exploring ways to improve the warfighter as a living organism. The relevant practices could be called "biomedical human performance enhancement," which sets them apart from more conventional ways of improving performance, such as training and equipment. Human enhancement raises a range of ethical, legal and social issues - both in the military context and in society more broadly. In the military context, issues arise under the law of armed conflict (LOAC). After providing a brief conceptual and technical background to human enhancement, this paper considers a set of LOAC issues relating to human enhancement by asking two broad questions: First, does LOAC prohibit or restrict the enhancement of warfighters? Second, if warfighters are enhanced in some way, what consequences does that have under LOAC?

Dr Rain Liivoja is an Associate Professor at the University of Queensland Law School, where he leads the Law and the Future of War Research Group [r.liivoja@uq.edu.au].

This research was supported by a Branco Weiss Fellowship. The author is grateful to the participants of the Law of Armed Conflict 2040 Workshop, hosted by the Lieber Institute for Law and Land Warfare, for comments on an earlier draft.

An edited version of this paper will appear as a chapter in THE FutURE LAW OF ARMED CONFLICT (Matthew Waxman and Thomas W. Oakley eds., Oxford University Press, forthcoming in 2021). 


\section{Contents}

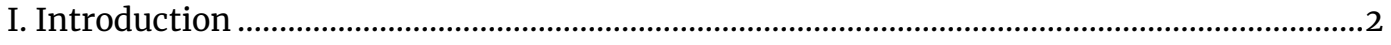

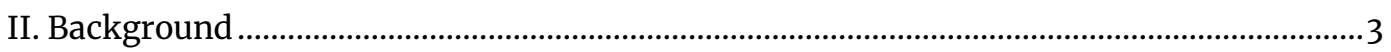

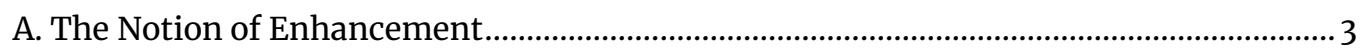

B. Examples of Human Enhancement........................................................................................6

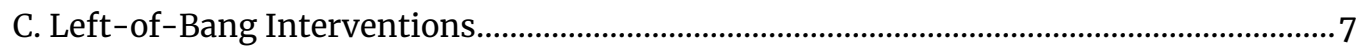

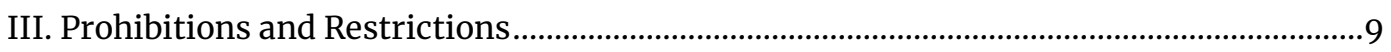

A. Rules on Weapons, Means and Methods of Warfare...........................................................

B. Duty to Respect and Ensure Respect........................................................................... 12

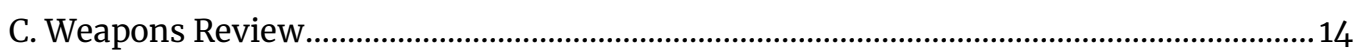

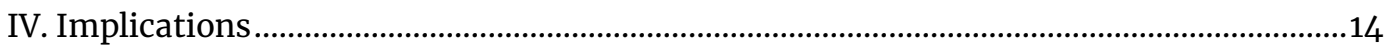

A. Individual Accountability for Unlawful Acts …………….............................................14

B. Protection of Medical Personnel .................................................................................18

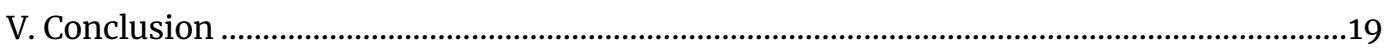

\section{Introduction}

Warfighters are both the strongest and the weakest link of an armed force. The parallel processing capability of the human brain, and the agility of the human body, are still unmatched by technology. At the same time, as human beings, warfighters have obvious limitations. They require oxygen, water, nutrition and sleep to survive. They are not adapted to certain things that other species excel at, such as seeing in the dark, travelling very fast or long distances, or carrying heavy loads. They are also susceptible to illnesses and injuries.

Armed forces understandably wish to mitigate these factors. The most common way to do so is by using equipment, such as body armour or night-vision devices. But that only goes so far. Equipment has its own limitations - it must be lugged around, it can be affected by the elements, and so on. Technologically advanced armed forces have therefore begun exploring ways to improve the warfighter as a living organism. Significant headway will no doubt have been made in this respect by 2040 . The relevant practices could be called "biomedical human performance enhancement," as distinct from improvements in performance resulting from training or equipment. Such interventions are more commonly referred to simply as "human enhancement" or they may take place under more innocuous banners, such as "performance maintenance" or "performance optimisation."

Human enhancement raises a range of ethical, legal and social issues - both in the military context and in society more broadly. ${ }^{1}$ The most obvious legal issues

\footnotetext{
${ }^{1}$ See generally, Human EnHANCEMENT (Julian Savulescu \& Nick Bostrom eds., 2010); MichaEL Bess, MAKE WAY For THE SUPERHUMANS: HOW THE SCIENCE OF BIO-ENHANCEMENT Is TRANSFORMING OUR WORLD, AND How We NeED to DEAL With IT (2016); THE ETHICS OF HuMAN ENHANCEMENT: UNDERSTANDiNG THE Debate (Steve Clarke et al. eds., 2016); Allen E. Buchanan, Better Than Human: The Promise And PERILS OF ENHANCING OURSELVES (2017).
} 
relate to the regulation of drugs and medical devices, and the extent to which the existing legal framework applies to, and appropriately addresses, their nontherapeutic uses. ${ }^{2}$ Also, questions about human rights are bound to arise. Different human enhancement techniques involve the ingestion or injection of drugs, implantation of devices, electromagnetic radiation of tissues and organs, and so on, often on an experimental basis. Not only does international human rights law imply the right to bodily integrity, ${ }^{3}$ it expressly prohibits nonconsensual medical experimentation, ${ }^{4}$ thus giving rise to the requirement of informed consent.

In the military context, issues also arise under the law of armed conflict (LOAC). However, human enhancement has been a difficult topic for the LOAC discourse because it does not fit neatly into the prevailing regulatory boxes - the conduct of hostilities or the protection of persons not taking part in hostilities. Hence, the legal (as distinct from ethical) literature on military human enhancement remains scarce. ${ }^{5}$

In this paper, I consider a set of LOAC issues relating to human enhancement. I do so by asking two broad questions: First, does LOAC prohibit or restrict the enhancement of warfighters? Second, if warfighters are enhanced in some way, what consequences does that have under LOAC? I turn to these questions, respectively, in Sections III and IV of this paper. Before doing so, I provide a brief conceptual and technical background to human enhancement in Section II.

\section{Background}

\section{A. The Notion of Enhancement}

Human enhancement, particularly in the military context, can be easily sensationalised. Newspaper headlines refer to "super soldiers," "ultimate human killing machines," "electrocuting brains" and so forth. ${ }^{6}$ This is hyperbole.

\footnotetext{
${ }^{2}$ See, e.g., Hannah Maslen et al., The Regulation of Cognitive Enhancement Devices: Extending the Medical Model, 1 J. L. \& BIosci. 68 (2014).

${ }^{3}$ This derives from the prohibition of inhuman treatment and the right to privacy, which are recognised in the International Covenant on Civil and Political Rights, arts. 7 and 17, Dec. 16, 1966, 999 U.N.T.S. 171.

${ }^{4}$ Id. art. 7.

${ }^{5}$ But see Heather A. Harrison Dinniss \& Jann K. Kleffner, Soldier 2.0: Military Human Enhancement and International Law, 92 INT'L. L. STUD. 432 (2016); Heather A. Harrison Dinniss, Legal Aspects of Human Enhancement Technologies, in NEW TECHNOLOGIES AND THE LAW IN WAR AND PEACE 230 (William H. Boothby ed., 2018).

${ }^{6}$ Michael Hanlon, "Super Soldiers": The Quest for the Ultimate Human Killing Machine, THE INDEPENDENT ONLINE, 2011, www.independent.co.uk/news/science/super-soldiers-the-quest-for-the-ultimatehuman-killing-machine-6263279.html; Mark Prigg, US Air Force Experiments Create "Supersoldiers" with Enhanced Mental Skills by Boosting Brains with Electric Shocks, DAILY MAIL ONLINE, November 8, 2016, www.dailymail.co.uk/sciencetech/article-3914600; Chris Pleasance, How to Build a Super-
} 
Human enhancement, at least in the short and medium term, entails a moderate improvement of some aspect of human performance by means of fairly common interventions, rather than the creation of warfighters with truly superhuman characteristics through some extraordinary scientific feats. That, however, suggests that social resistance to enhancement, particularly in the armed forces, will be limited, and legal issues arising from enhancement will have increasing practical significance.

In an occupational context, such as service in the armed forces, human abilities broadly fall into four categories: cognitive, physical, psychomotor and sensory: ${ }^{7}$

- cognitive abilities include verbal expression and comprehension, idea generation and reasoning, memorisation, object and pattern perception, spatial orientation and attentiveness;

- physical abilities encompass muscular strength, cardiovascular endurance, and movement quality (flexibility, balance and coordination);

- psychomotor abilities cover fine manipulation, movement control, and reaction time and speed;

- sensory abilities relate to visual, auditory, olfactory and tactile capabilities.

Any of these specific abilities could be targeted by human enhancement techniques although the benefits obviously depend on the tasks of warfighters. Thus, improvements in the sense of smell would probably have limited utility, whereas gains in perception, attentiveness, endurance or vision could be quite significant. The possibility of achieving a comparable performance improvement through training or equipment also needs to be considered. For example, improving vision in low light conditions by means of night-vision devices seems to be safer and more cost-effective than attempting to increase the light sensitivity of the retina. Also, enhancement of some ability (say, distance vision) will ultimately start to impair other abilities (say, near vision).

The techniques involved in human enhancement are varied: depending on the ability targeted, enhancement could be achieved by pharmacological, surgical, electromagnetic or genetic means, or some combination thereof (for example, an implant releasing a drug). Many of the interventions in question can also be used therapeutically to manage various maladies. Indeed, often an intervention is originally developed as a form of therapy, and later applied as an enhancement. Consequently, defining enhancement and distinguishing it from treatment becomes a difficult task. At bottom, enhancement refers to "biomedical interventions that are used to improve human form or functioning beyond what

Soldier: US Military Experiments with ELECTROCUTING Recruits' Brains to Improve Their Reaction Times, DAILY MAIL ONLINE, April 3, 2017, www.dailymail.co.uk/news/article-4375560.

${ }^{7}$ See generally Joyce Hogan, Structure of Physical Performance in Occupational Tasks, 76 J. APPL. PsychOL. 495 (1991); EdWin A. Fleishman \& MAUREEn E. Reilly, HaNdBooK of Human AbILITIES: Definitions, MEASUREMENTS, AND JOB TASK REQUIREMENTS (1992). 
is necessary to restore or sustain health." 8 In other words, enhancement makes people "better than well." 9 But drawing a line between health and superior performance, or between therapy and enhancement, poses difficulties.

It is probably true to say that there are "countless" instances where the distinction is "unambiguously clear." 10 Giving warfighters abilities that no human has would plainly amount to enhancement. For instance, if it were possible to transplant a human with gills, allowing them to live underwater, ${ }^{11}$ the procedure would doubtless constitute enhancement.

Matters become complicated when dealing with abilities possessed by all or most humans but to a different degree. Consider human vision, specifically visual acuity, as measured by a Snellen chart. It has been suggested, quite reasonably, that interventions to correct vision below 20/20 would be therapy whereas "vision that is beyond this level is an example of enhancement." ${ }^{12} \mathrm{~A}$ person with 20/20 vision can see from 20 feet what an average person can see from 20 feet. This does not mean perfect vision: better than $20 / 20$ vision occurs naturally in the human population. Indeed, if 20/20 represents the statistical median and visual acuity is normally distributed, ${ }^{13}$ half of the population would have better than 20/20 vision. Why then should the improvement of vision beyond 20/20 necessarily be deemed an enhancement? Also, consider two people having refractive surgery: one starts off with visual acuity of 20/40 (not great but acceptable for driving a car in many jurisdictions) and the other with 20/20 ("normal"). Both end up with 20/10 vision (better than "normal"). Are both of these instances of enhancement? Only the second?

In summary, one of the major difficulties of looking at the legal implications of enhancement is that there are circumstances where it becomes incredibly difficult to say what does and what does not qualify as enhancement. This should caution against reaching broad black-and-white conclusions under some legal rule, or in relation to some intervention. What seems to be required in many instances is a contextual analysis that looks at the nature of a particular intervention, and its intended and likely effects.

Some commentators include in the notion of enhancement not only modifications to physiological processes and devices integrated into the body, but also any

\footnotetext{
${ }^{8}$ Eric Juengst \& Daniel Moseley, Human Enhancement, in THE STANFORD ENCYCLOPEDIA OF PHILOSOPHY (Edward N. Zalta ed., 2016), plato.stanford.edu/archives/spr2016/entries/enhancement/.

${ }^{9}$ Carl Elliott, Better Than Well: American Medicine MeEts the American Dream (2003).

${ }^{10}$ See, e.g., Ioana Maria Puscas, Military Human Enhancement, in NEW TECHNOLOGIES AND THE LAW IN WAR AND PEACE 182 (William H. Boothby ed., 2018).

${ }^{11}$ This is the premise of a Soviet science fiction classic: AlEXANDER BELYAEV, THE AMPHIBIAN (R. Dixon ed., L. Kolesnikov tran., 1959).

${ }^{12}$ See, e.g., Puscas, supra note 10.

${ }^{13}$ Population-wide statistical data on this point is surprisingly difficult to come by.
} 
"ability ... [that is] so closely worn or connected that it confers an advantage similar to an internal or organic enhancement that transform the person." ${ }^{14}$ This approach is problematic in that it would classify as enhancement various devices that are better seen as sophisticated equipment but equipment nonetheless. One example would be the Tactical Assault Light Operator Suit (TALOS), an exoskeleton system to provide "full-body load transfer, while dramatically improving the physical performance of an operator," which the U.S. Special Operations Command was working on until 2019. ${ }^{15}$ Even though TALOS would have been "closely worn," it was a robotic suit, not raising the same legal or bioethical questions as interventions that affect bodily integrity, such as drugs or implants.

\section{B. Examples of Human Enhancement}

As already mentioned, enhancement can have broadly two aims - giving individuals abilities not ordinarily possessed by humans or improving some human ability beyond what might be regarded as normal.

One obvious example falling into the first category is a brain-computer interface (BCI), also known as a brain-machine interface. BCI is a system that allows the brain to communicate with an external device directly, i.e. without using natural neuromuscular pathways. ${ }^{16}$ Much of the impetus for research and development in this context comes from the desire to make better prostheses - artificial limbs that could be controlled by thought along. But the technology plainly has a broader range of applications: it could be used to control vehicles and weapons systems, shaving off valuable milliseconds that operators would normally need to control a device by manual or voice commands.

Depending on how a particular BMI obtains bioelectrical signals from the brain, it could be seen as merely equipment or as human enhancement. If the BMI comes in the form of a headset, or is integrated into a helmet, it would qualify as equipment. If, however, to obtain a cleaner signal, electrodes were placed intracranially, the device would become a form of human enhancement.

As for improving existing human traits, pharmacological enhancement is by far the most common and has been practiced for centuries. ${ }^{17}$ Indeed, countless people

\footnotetext{
${ }^{14}$ Harrison Dinniss and Kleffner, supra note 5 at 434.

${ }^{15}$ Ryan Devereaux, "Iron Man" Suit Lives on in Dreams of Special Operations Commanders, THE INTERCEPT, June 2, 2015, theintercept.com/2015/06/02/special-operations-iron-man-suit-lives; Jared Keller, SOCOM's Iron Man Suit Is Officially Dead, TASK \& PURPOSE, February 15, 2019, taskandpurpose.com/talos-iron-man-suit-dead.

${ }^{16}$ See, e.g., Bin He, Brain, Computer and Machine Interfacing, in NEUROMODULATION: COMPREHENSIVE TeXtbook of Principles, Technologies, and Therapies 339 (Elliot S. Krames, P. Hunter Peckham, \& Ali R. Rezai eds., 2nd ed. 2018).

${ }^{17}$ See generally ŁUKASZ KAMIEŃSKi, SHOOTING UP: A HiStory of DRUGS AND WAR (2016).
} 
drink coffee daily to improve alertness - i.e. for enhancing cognitive abilities. However, more potent central nervous system stimulants have been, and are being, used as "pharmacological fatigue countermeasures." For example, the use of dexamphetamine and modafinil (Provigil ${ }^{\circledR}$ ) is authorised in the U.S. armed forces under strict medical supervision and when administrative fatigue countermeasures are deemed insufficient. ${ }^{18}$ As far as physical abilities go, it has also been suggested that medically supervised use of anabolic-androgenic steroids ought to be investigated and considered. The 5 to 20 per cent increase in muscle strength that may be expected from the controlled use of steroids "would be a significant improvement in load carriage of dismounted soldiers." 19

Various forms of non-invasive neurostimulation also hold promise for enhancement. For example, transcranial direct current stimulation (tDCS), where areas of the brain are stimulated by delivering low direct current to the scalp, has been found to accelerate learning of threat detection, ${ }^{20}$ and to improve, in sleep deprived individuals, attention/vigilance, reaction times, accuracy and mood. ${ }^{21}$

\section{Left-of-Bang Interventions}

In addition to improving particular abilities of warfighters beyond typical levels, armed forces also have an interest in making warfighters more resilient and protecting them against injury. Traditionally, the principal technological way of reducing the risk of injury from hostile enemy action has been protective gear, such as helmets or body armour. But the survivability of warfighters could also be improved by means of pre-emptive biomedical interventions. These so-called "left-of-bang interventions" refer to "any medical, pharmacologic, or surgical intervention that is delivered before trauma and may act to reduce morbidity and mortality after injury." 22

The two most frequent causes of warfighter incapacitation are acute haemorrhage and intractable pain. ${ }^{23}$ Indeed, haemorrhage has been a major

\footnotetext{
${ }^{18}$ Nicholas Davenport, Cheryl Lowry \& Brian Pinkston, Use of Stimulants in Operational Settings: Issues and Considerations, in SLEep Deprivation, Stimulant MEdiCATIONS, AND Cognition 237 (Nancy J. Wesensten ed., 2012).

${ }^{19}$ Paul Scharre \& Lauren Fish, Human Performance Enhancement 6 (2018).

${ }^{20}$ R. Andy McKinley et al., Acceleration of Image Analyst Training with Transcranial Direct Current Stimulation, 127 BEHAV. NEUROSCI. 936 (2013).

${ }^{21}$ Lindsey K. McIntire et al., Transcranial Direct Current Stimulation Versus Caffeine as a Fatigue Countermeasure, 10 BRAIN STIMUL. 1070 (2017).

${ }^{22}$ Neil M. Eisenstein et al., Pretrauma Interventions in Force Health Protection: Introducing the "Left of Bang" Paradigm, 16 J. SPECIAL OPERATIONS MED. 59 (2016).

${ }^{23}$ Joseph T. Bielitzki, Enhancing Human Performance in Combat 4 (2002), archive.darpa.mil/DARPATech2002/presentations/dso_pdf/speeches/BIELITZ.pdf.
} 
mechanism of death in potentially survivable combat injuries. ${ }^{24}$ It is therefore unsurprising that bleeding and pain have featured prominently in the left-ofbang paradigm.

By way of example, one drug mentioned in this context is tranexamic acid (TXA). This is a common antifibrinolytic agent, i.e. a drug that slows the breakdown of blood clots. While TXA is primarily intended for use in the management of bleeding disorders, it has been widely used in surgical patients because of its efficacy in reducing surgical-associated bleeding and transfusion requirements. ${ }^{25}$ British Army surgeons have suggested that left-of-bang interventions, such as the prophylactic administration of TXA, should be considered for high risk warfighters, for example paratroopers dropping into enemy-held rocky territory at night. ${ }^{26}$

In the early 2000s, DARPA's established a "Persistence in Combat" program, which was looking to equip warfighters with non-invasive, self-administrable therapeutics to control bleeding and pain and "dramatically accelerate" wound healing. ${ }^{27}$ The program included a search for a drug to control pain without, in contrast to opioids, reducing performance. ${ }^{28}$ The result was tanezumab, a monoclonal antibody directed against a neuropeptide know as nerve growth factor (NFG). NFG is produced and released by peripheral tissue in the event of tissue damage and acts as an important pain mediator. ${ }^{29}$ Tanezumab's half-life exceeds 12 days and at higher doses approaches 24 days. ${ }^{30}$ Thus, while DAPRA's vision may have been for an analgesic that can be self-administered subsequent to injury, tanezumab or a similar drug could potentially be used prior to a military operation to control pain in the event of an injury. ${ }^{31}$ Thus, the claim made by

\footnotetext{
${ }^{24}$ Brian J. Eastridge et al., Died of Wounds on the Battlefield: Causation and Implications for Improving Combat Casualty Care, 71 J. TRAUMA S4 (2011).

${ }^{25}$ Jason Taam et al., Current Evidence and Future Directions of Tranexamic Acid Use, Efficacy, and Dosing for Major Surgical Procedures, 34 J. CARDIOTHORAC. VASC. ANESTH. 782 (2020).

${ }^{26}$ Eisenstein et al., supra note 22.

${ }^{27}$ Committee on ARmed Services, United States Senate, 107Th Congress, Department of Defense Authorization for Appropriations for Fiscal Year 2003 - Part 5: Emerging Threats and Capabilities 184 (2002) (Testimony of Dr Tony Tether, Director, DARPA).

${ }^{28}$ Noah Shachtman, Saving Pvt. Ryan ... From Pain, WIRED, October 10, 2003, www.wired.com/2003/10/saving-pvt-ryan-from-pain.

${ }^{29}$ See, e.g., Steven P. Cohen et al., Anti-nerve Growth Factor in Pain Management: Current Evidence, 9 J. PAIN RES. 373 (2016); Franziska Denk, David L. Bennett \& Stephen B. McMahon, Nerve Growth Factor and Pain Mechanisms, 40 ANNU. Rev. NEURosCI. 307 (2017).

${ }^{30} \mathrm{H}$. Nagashima et al., Preliminary Assessment of the Safety and Efficacy of Tanezumab in Japanese Patients with Moderate to Severe Osteoarthritis of the Knee: A Randomized, Double-Blind, Dose-Escalation, Placebo-Controlled Study, 19 OSTEOARTHR. CARTIL. 1405 (2011).

${ }^{31}$ Shachtman, supra note 28.
} 
DARPA - and liberally reprinted by the media - about the development of a "pain vaccine" was, at least figuratively, not entirely spurious.

In summary, there are numerous biomedical interventions that are already being used, or could be used, to improve the abilities of warfighters or to increase their survivability. There is little doubt that the rapid advancement of biomedical sciences will lead to new ways to enhance human performance as well as improve existing methods. Whether it will be possible to speak of true supersoldiers in 2040 is uncertain. But one can safely assume that human enhancement will become a far more common and multifaceted phenomenon than it is today.

\section{Prohibitions and Restrictions}

The prospects of adopting new military technologies frequently leads to claims that the envisaged use of the technology would already be prohibited by the law, and, if it is not, it should be. The attempts to ban "killer robots" or to prevent the "militarisation of cyberspace" provide some contemporary examples of this kind of thinking. There is undeniable appeal to such proposals. They would maintain the status quo, reducing the need for a complex and potentially divisive discussions as to how the technology could be used consistently with LOAC and indeed whether the use of the technology might lead to a higher degree of LOAC compliance. Enhancement is no different: some of the early legal analyses displayed some scepticism about the legality of such interventions.

\section{A. Rules on Weapons, Means and Methods of Warfare}

In 2013, the Greenwall Foundation published a report that provided a useful overview of enhancement technologies that might have military uses, and undertook an initial review of some of the ethical and legal issues involved. ${ }^{32}$ Among other things, the authors of the report argued that enhanced warfighters constituted biological weapons and that their deployment would therefore be prohibited by the Biological Weapons Convention. ${ }^{33}$ This line of reasoning placed a heavy emphasis on the words "biological agents" used in the Convention. ${ }^{34}$ This phrase, so the argument went, was capable of capturing enhanced human beings - being "biological" as distinct from purely chemical or physical, and being "agents" in the way that this word is used for, say, secret agents. ${ }^{35}$

\footnotetext{
${ }^{32}$ Patrick Lin, Maxwell J Mehlman \& Keith Abney, Enhanced Warfighters: Risk, Ethics, ANd Policy (2013).

${ }^{33}$ Id. at 31-2.

${ }^{34}$ Convention on the Prohibition of the Development, Production and Stockpiling of Bacteriological (Biological) and Toxin Weapons and on Their Destruction art. I, Apr. 10, 1972, 26 U.S.T. 583, 1015 U.N.T.S. 163.

${ }^{35}$ Lin, MEHLMAN, AND ABNEY, supra note 32 at 31.
} 
This argument, though creative, fails for number of reasons. It is inconsistent with the accepted meaning of "biological agents," as well as the object and purpose, and the drafting history, of the Convention. ${ }^{36}$ Also, it raises the question as to what kind of enhancement - and, indeed, if any - would be required to turn warfighters into a prohibited "biological agents." The argument appears to have been abandoned by those who initially advanced it - the claims based on the Biological Weapons Convention are conspicuously absent from a book chapter based on the Greenwall Foundation report. ${ }^{37}$

But a valid broader question arises here as well. Could enhanced warfighters be weapons for the purposes of LOAC? Could they be means of warfare? Could their use be a method of warfare? As I have argued elsewhere, the prospect of a human being constituting as a weapon under LOAC seems slim. ${ }^{38}$ That might that be the case only in circumstances where a human being is purely used as an instrument of warfare - a body or an inanimate object. Accordingly, it seems highly unlikely that a warfighter, enhanced though they might be, would qualify as a weapon and therefore fall to be regulated by any arms control instrument or weapon-specific rule of customary law.

There is more to be said about the idea that enhanced warfighters could be means of warfare. That would seem to be the case where warfighters are so closely integrated with weapons - for example through BCIs - that they effectively become part of weapon systems. Also, it is conceivable that the operation of some military technology or some other tactic becomes so dependant on the enhancement of warfighters that the enhancement becomes an aspect of a method of warfare.

Accordingly, there are circumstances, though limited, where the LOAC rules that extend to means and methods of warfare would place constraints on the use of human enhancements (or, to be more precise, the fielding of warfighters who have been enhanced). For States party to Additional Protocol I, which regulates weapons, means and methods of warfare together, the enhancement would be prohibited if it gave rise to a means or method of warfare (i) of a nature to cause superfluous injury or unnecessary suffering, (ii) of a nature to strike military and

\footnotetext{
${ }^{36}$ Rain Liivoja \& Luke Chircop, Are Enhanced Warfighters Weapons, Means, or Methods of Warfare?, 94 INT'L. L. STUD. 161, 166-172 (2018).

${ }^{37}$ Patrick Lin et al., Super Soldiers (Part 2): The Ethical, Legal, and Operational Implications, in GLOBAL IsSUES AND ETHICAL CONSIDERATIONS IN HuMAN ENHANCEMENT TECHNOLOGIES 139 (Steven John Thompson ed., 2014).

${ }^{38}$ Liivoja and Chircop, supra note 36.
} 
civilian object without distinction, or (iii) of a nature to cause serious environmental harm. ${ }^{39}$

The rules concerning environmental protection can probably be cast aside reasonably quickly. It is difficult to see what enhancement might lead to environmental harm so significant as to be captured by the rules of Additional Protocol I.

The prohibition of means and methods of warfare of a nature to cause superfluous injury and unnecessary suffering would perhaps be somewhat more relevant. The only way a difficulty might arise under this rule is if the enhanced warfighters were capable of inflicting unnecessarily gruesome injuries with their bare hands and that this was indeed the normal intended use for such warfighters. This seems unlikely. The prohibition would become marginally more pertinent if one were to accept that it prohibits the causing of superfluous injury or unnecessary suffering more broadly. If that is the case, one could argue that the enhanced warfighters are prohibited from utilising their superior strength in a manner that causes unnecessary suffering.

Some commentators suggest that the rule in question protects warfighters against being enhanced in a manner that causes them superfluous injury of unnecessary suffering. ${ }^{40}$ That is not the case: the unnecessary suffering rule operates to protect the combatants of the adversary against needlessly cruel weapons, means or methods of warfare. Whether the enhancement causes unjustifiable pain, suffering or some other harm to the warfighters who are being enhanced would need to be assessed under the relevant considerations of bioethics, domestic law and international human rights law - not LOAC.

The prohibition on inherently indiscriminate means and methods of warfare has perhaps the most relevance in the context of enhancement. Let us take a weapon that, when operated manually, is sufficiently discriminate. Let us imagine that this weapon is instead controlled by a warfighter using a BCI resulting in a faster operation of the weapon but with decreased accuracy. Depending on how much accuracy decreases, using the weapon system (made up of the weapon, the BCI and the warfighter) could be in breach of the prohibition of indiscriminate means and methods of warfare.

In conclusion, the LOAC rules dealing with weapons, means and methods of warfare are of some limited relevance to assessing the legality of enhancement techniques. Certainly, LOAC gives rise to no outright prohibition of enhancement;

\footnotetext{
${ }^{39}$ Protocol (I) Additional to the Geneva Conventions of 12 August 1949, and Relating to the Protection of Victims of International Armed Conflicts art. 35, June 8, 1977, 1125 U.N.T.S. 3 (hereinafter Additional Protocol I).

${ }^{40}$ Vincent Boulanin \& MaAike Verbruggen, ARticle 36 Reviews: Dealing With the Challenges Posed by EMERGING TECHNOLOGIES 29 (2017).
} 
indeed, various methods of enhancement, such as the use of caffeine, seem to be wholly unproblematic from a legal point of view. The general principles of LOAC pertaining to weapons, means and methods of warfare would, at most, rule out some fairly invasive and unreliable enhancements, for the use of which there would be little military incentive.

\section{B. Duty to Respect and Ensure Respect}

The most significant restrictions on enhancement arises, however, outside the context of weapons, means and methods of warfare. I would argue that LOAC prohibits the use of any enhancing intervention that diminishes the ability of the warfighter to comply with the law.

I contend, for example, that the administration of a drug for enhancement purposes would be unlawful under LOAC if it had an adverse effect on the warfighters' capacity to make judgments required by the law, for example by making them disinhibited and more impulsive, or reducing their inclination to critically evaluate the lawfulness of orders given to them. Consider, for instance, the widely reported supply of a variety of stimulant drugs - including a concoction called brown-brown, a mixture of cocaine and gunpowder - to child soldiers in West African armed conflicts. ${ }^{41}$ Quite aside from contravening the prohibition on the recruitment and use of child soldiers, ${ }^{42}$ this practice also falls afoul of LOAC because it makes the children more violent and more likely to perpetrate violations of LOAC. ${ }^{43}$

The restriction that I have outlined is, of course, not expressly mentioned in any LOAC instrument. But derives from the fabric of this body of law. Most generally, the duty not to use enhancements that reduce compliance with LOAC can be based on the obligation to perform LOAC treaties in good faith. ${ }^{44}$ More specifically, the restrictions derives from the obligation of States "to respect and to ensure respect" for LOAC in all circumstances. This obligation is expressly stipulated in Common Article 1 to the Geneva Conventions, ${ }^{45}$ as well as in Additional Protocols

\footnotetext{
${ }^{41}$ See, e.g., Ishmael Beah, The Making, and Unmaking, of a Child Soldier, INTERNATIONAL HERALD TRIBUNE, January 14, 2007, www.nytimes.com/2007/01/14/world/americas/14ihtweb.0113soldier.nytMAG.4195623.html.

42 See especially Additional Protocol I, supra note 39, art. 77(2); Protocol (II) Additional to the Geneva Conventions of 12 August 1949, and Relating to the Protection of Victims of Non-International Armed Conflicts art. 4(3)(c), June 8, 1977, 1125 U.N.T.S. 609; Convention on the Rights of the Child art. 38(3), Nov. 20, 1989, 1577 U.N.T.S. 3; Optional Protocol to the Convention on the Rights of the Child on the Involvement of Children in Armed Conflict, May 25, 2000, 2173 U.N.T.S. 222.

${ }^{43}$ On the effects of these drugs see, e.g., Luz E. Nagle, Child Soldiers and the Duty of Nations to Protect Children from Participation in Armed Conflict, 19 CARDOZO J. INT'L \& COMP. L. 1, 10 (2011).

${ }^{44}$ Vienna Convention on the Law of Treaties art. 26, May 23, 1969, 1155 U.N.T.S. 331.

${ }^{45}$ Geneva Convention (I) for the Amelioration of the Condition of the Wounded and Sick in Armed Forces in the Field art. 1, Aug. 12, 1949, 6 U.S.T. 3114, 75 U.N.T.S. 31; Geneva Convention (II) for the Amelioration of the Condition of Wounded, Sick, and Shipwrecked Members of the Armed Forces at
} 
I and II to the Conventions. ${ }^{46}$ There is no serious doubt about the obligation also having a basis in customary international law. There is, however, considerable controversy as to the precise meaning and implications of this rule. In particular, no consensus exists as to whether "ensure respect" has an external dimension, which would entail an obligation to attempt to secure compliance with the law by other States, international organisations and non-state armed groups. ${ }^{47}$

It is not necessary to traverse that territory here. My claim is based squarely on the uncontroversial "internal compliance dimension" 48 of the rule. According to this aspect of the rule, States are, among other things, under an obligation to "put a stop to[,] and proactively prevent[,] infringements of the Geneva Conventions by their own organs, namely their armed forces." ${ }^{49}$ Plainly the supply of drugs to members of the armed forces that increases the likelihood of infringements of the law would conflict with this LOAC requirement.

This view immediately raises the question as to whether a State is under an obligation to utilise an enhancement if can be expected to reduce the incidence of infringements of the law or, even more broadly, to have beneficial humanitarian consequences that are in line with the objectives of the law. For example, it might be possible to show that the provision of stimulants to sleep deprived troops increases their ability to take precautionary measures in attack, such as the verification of targets and the reduction of collateral damage. ${ }^{50}$ Would this make it a legal obligation of the State to provide such stimulants?

Providing an affirmative answer would run into various difficulties. To name just a few, the State might not have access to the appropriate drugs, or it might not have sufficient supplies of the drugs available. The effects of the drug on an individual might vary and be medically contraindicated for some. So, the prohibition of legally adverse enhancement seems to be more realistic than a duty to undertake legally beneficial enhancements.

\footnotetext{
Sea art. 1, Aug. 12, 1949, 6 U.S.T. 3217, 75 U.N.T.S. 85; Geneva Convention (III) Relative to the Treatment of Prisoners of War art. 1, Aug. 12, 1949, 6 U.S.T. 3316, 75 U.N.T.S. 135; Geneva Convention (IV) Relative to the Protection of Civilian Persons in Time of War art. 1, Aug. 12, 1949, 6 U.S.T. 3516, 75 U.N.T.S. 287.

${ }^{46}$ Additional Protocol I, supra note 39, art. 1(1); Protocol Additional (III) to the Geneva Conventions of 12 August 1949, and relating to the Adoption of an Additional Distinctive Emblem art. 1(1), Dec. 8, 2005, 2404 U.N.T.S. 261.

${ }^{47}$ For an articulation of an expansive obligation, see, e.g., Jean-Marie Henckaerts, Article 1: Respect for the Convention, in COMmENTARY ON THE SECOND GENEVA CONVENTION: CONVENTION (II) FOR THE Amelioration of THE CONDition of Wounded, SiCK AND SHiPWRECKED MEMBERS OF ARMED Forces AT SEA 43, 56-68 (Knut Dörmann et al. eds., 2017).

${ }^{48}$ Robin Geiß, The Obligation to Respect and to Ensure Respect for the Conventions, in THE 1949 GENEVA Conventions: A Commentary 111, 117, II 10 (Andrew Clapham, Paola Gaeta, \& Marco Sassòli eds., 2015).

${ }^{49}$ Id. at 118 , II 13.

${ }^{50}$ Additional Protocol I, supra note 39, art. 57.
} 


\section{Weapons Review}

All States are arguably under a customary law obligation to undertake a legal review of a new weapon prior to its use. ${ }^{51}$ For States party to Additional Protocol I, this is a treaty-based obligation that also extends to new means and methods of warfare, and the study and design phase. ${ }^{52}$ Accordingly, those States would need to assess the compliance of enhancements that amount to means and methods of warfare with international law, which in particular would include the principles outlined earlier.

Enhancement creates some novel challenges. Normally, when a weapon and its associated systems or methods of warfare are addressed, the reviewer can assume that the weapons performs similarly in the hands of different warfighters - in other words, that the human element introducing any inaccuracy remains fairly stable. So, for example, to assess the lawfulness of a particular projectile, a series of test shots might be fired to establish a circular error probable, but it would not be necessary to have a large sample of warfighters fire those shots. With BMI, on the other hand, that might be necessary. The accuracy of the weapon when controlled by a BMI might be highly dependent on the individual warfighter such that, as with clinical trials of medical devices, a sample of warfighters would need to be tested. This is no doubt possible but would require a rethinking of existing legal review protocols.

\section{Implications}

The use of enhancement can have legal consequences, quite independently of whether the enhancement itself is lawful or unlawful under the rules discussed previously. In particular, there may be consequences for the warfighter who has been enhanced and the individual administering the enhancement.

\section{A. Individual Accountability for Unlawful Acts}

In light of the earlier discussion of enhancements that reduce the ability of warfighters to comply with the law, it needs to be considered what would be the legal effects on individual (criminal) accountability if the warfighters' ability to comply with the law was in fact adversely affected by the enhancement. This is not an entirely hypothetical problem, which might or might not materialise by 2040. This is an issue of practical significance that has already arisen in relation to the use of amphetamines as a fatigue countermeasure.

\footnotetext{
${ }^{51}$ Compare Duncan Blake \& Joseph S. Imburgia, "Bloodless Weapons"? The Need to Conduct Legal Reviews of Certain Capabilities and the Implications of Defining Them as "Weapons", 66 AIR FORCE L. REV. 157 (2010); Natalia Jevglevskaja, Weapons Review Obligation under Customary International Law, 94 INT'L. L. STUD. 186 (2018).

${ }^{52}$ Additional Protocol I, supra note 39, art. 36.
} 
In the early morning hours of 18 April 2004, two US F-16 fighter aircraft were airborne over South East Afghanistan. They were returning to their base in Kuwait after a combat air patrol. Near the city of Kandahar, the pilots saw flashes on the ground which they perceived as surface-to-air fire directed at them. After some back and forth between the flight lead, the wingman and mission controllers, the wingman proceeded to release a 500-pound laser-guided bomb. The bomb hit what were in fact a group of Canadian light infantry soldiers engaged in a night live-fire training exercise. Four Canadians were killed and eight wounded. A joint US-Canadian Coalition Investigation Board concluded that the incident was caused by the failure of the wingman to exercise "appropriate flight discipline" and the failure of the fight lead to exercise "appropriate flight leadership." 53 The US co-president of the Board recommended that "appropriate disciplinary action, up to and including trial by general court-martial," be taken against both pilots. ${ }^{54}$

One of the issues raised in the subsequent investigative hearing (the Article 32 hearing ${ }^{55}$ ) was the use of pharmacological fatigue countermeasures. Some two hours before the incident, both pilots had ingested dexamphetamine - the wingman $10 \mathrm{mg}$ and the flight lead $5 \mathrm{mg} .{ }^{56}$ The defence counsel reportedly argued that "given the drug's potential side effects - which can include agitation, paranoia, and psychosis - it is dangerous to dispense to fighter pilots, and could have affected their ... judgment." ${ }^{57}$ It was also claimed that the Air Force routinely pressured pilots to take the pills. ${ }^{58}$

The US-Canadian report had considered, but ultimately dismissed, fatigue management medication as a factor in the pilots' substandard performance and the incident. ${ }^{59}$ The Article 32 judge considered this matter in some detail as well. He noted that the use of amphetamine "was certainly sanctioned, if not strongly encouraged." ${ }^{60}$ He went on to acknowledge that "[i]t would seem unfair to order pilots to fly long missions, provide them stimulants to fend off fatigue, and then hold them responsible if the stimulant affected their judgment." ${ }^{61}$ In the judge's opinion, amphetamine had no effect on the pilots' judgment in casu but that "the

\footnotetext{
${ }^{53}$ COALITION INVESTIGATION BOARD, REPORT: TARNAK FARMS, AFGHANISTAN 58 (2002).

${ }^{54}$ Id. at 61.

5510 U.S.C. $\$ 832$.

${ }^{56}$ COALITION InVESTIGATION BOARD, supra note 53 at 51; Davenport, Lowry, and Pinkston, supra note 18 at 248 .

${ }^{57}$ Robert Schlesinger, Defense Cites Stimulants in "Friendly Fire" Case, THE Boston GLOBE, January 4, 2003, www.globalsecurity.org/org/news/2003/030104-speedo1.htm.

${ }^{58} \mathrm{Id}$.

${ }^{59}$ COALITION INVESTIGATION BOARD, supra note 53 at 50-52.

${ }^{60}$ Cited in Michael Friscolanti, Friendly Fire: The Untold Story of THE U.S. Bombing That Killed FOUR CANADIAN SOLDIERS IN AFGHANISTAN 448 (2005).

${ }^{61}$ Cited in Id. at 448.
} 
pills raise an additional issue and could give court members an excuse to acquit in what may really be a jury nullification." 62 The Article 32 judge concluded that there was sufficient evidence to court martial both pilots but urged the commanding officer to drop criminal charges, taking the view that the interests of good order and discipline could be addressed adequately through lesser sanctions. ${ }^{63}$ In the end, the pilots were disciplined non-judicially: both were given a letter of reprimand, and the wingman also received a fine. ${ }^{64}$

Notwithstanding the final outcome of these proceedings, the Article 32 judge plainly recognised that there was a live issue with respect to the effect of amphetamine on the judgment of the pilots and the implications of that for individual criminal responsibility. While there was no suggestion that LOAC was breached, that would have been the case if the fire on the ground had come from, say, weapons fired during a wedding party.

The effect of drugs on human judgment in the context of a criminal trial would likely be examined through the lens of intoxication. The rules concerning the availability of intoxication as a defence differ significantly from jurisdiction to jurisdiction. ${ }^{65} \mathrm{~A}$ distinction, however, tends to be made between voluntary (selfinduced) and involuntary intoxication.

Most legal systems are reluctant to relieve a perpetrator from criminal responsibility where the perpetrator voluntarily induces a state of intoxication, and commits an offence in such a state. ${ }^{66}$ The specifics of the traditional approach under English law, which has also been adopted in some Australian jurisdictions, is convoluted. Self-induced intoxication can be invoked to show that the perpetrator lacked the necessary intent for "specific intent" crimes (such as murder or larceny) but not for "general intent" crimes (such as assault or rape). ${ }^{67}$ The distinction has been widely criticised as being arbitrary, unprincipled, and difficult (if not impossible) to apply in practice. ${ }^{68}$ In other jurisdictions, selfinduced intoxication can be raised more broadly to show that the perpetrator lacked the requisite mens rea - specifically, intent. The US Model Penal Code exemplifies this approach. ${ }^{69}$

\footnotetext{
${ }^{62}$ Cited in Id. at 448.

${ }^{63}$ David M. Halbfinger, Dismissal of Charges Recommended in "Friendly Fire" Case, THE NEW YoRK TIMES, March 21, 2003, www.nytimes.com/2003/03/21/us/dismissal-of-charges-recommended-infriendly-fire-case.html.

${ }^{64}$ See FRISCOLANTI, supra note 60 at 456-87.

${ }^{65}$ For a concise overview of the approaches, see KAI AMBOS, TREATISE ON INTERNATIONAL CRIMINAL LAW (2013) ch. 8(3).

${ }^{66}$ Id. ch. 8(3).

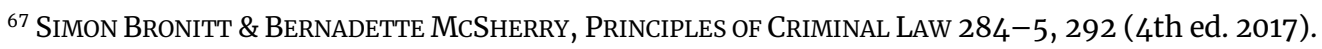

${ }^{68}$ See Id. at 293.; ANDREAS SCHLOENHARDT, QUEENSLAND CRIMINAL LAW 548 (5th ed. 2018).

${ }^{69}$ Model Penal Code $§ 2.08(1)$.
} 
The situation is quite different when it comes to involuntary intoxication. For example, in Australia, the federal Criminal Code expressly provides that "[a] person is not criminally responsible for an offence if the person's conduct constituting the offence was a result of intoxication that was not self-induced." 70 The Model Penal Code provides that involuntary intoxication is a defence where "the actor at the time of his conduct lacks substantial capacity either to appreciate its criminality [wrongfulness] or to conform his conduct to the requirements of law." ${ }^{71}$ In other words, involuntary intoxication tends to have more exculpatory potential.

Significantly, in a number of jurisdictions, intoxication resulting from the appropriate use of prescription medication would be deemed involuntary, even if the person was not compelled or tricked into ingesting the medication. For example, in the Australian state of New South Wales, self-induced intoxication excludes intoxication that

results from the administration of a drug for which a prescription is required in accordance with the prescription of a medical practitioner ... or of a drug for which no prescription is required administered for the purpose, and in accordance with the dosage level recommended, in the manufacturer's instructions. ${ }^{72}$

In a similar vein, the Model Penal Code excludes from the definition of selfinduced intoxication any intoxication caused by a substance introduced by a person into their body "pursuant to medical advice." 73

These carve-outs seem to be premised on the idea that a person should not be penalised for following a course of treatment, even if that treatment leads to intoxication, which in turn results in the commission of a crime. In circumstances where warfighters are prescribed drugs non-therapeutically for enhancement purposes, and these warfighters retain the freedom to take or not to take the drug, it is not clear how the resulting intoxication should be classified. Accordingly, it is unclear whether the more stringent test of self-induced intoxication, or the more relaxed test of involuntary intoxication, should be applied when potentially excusing the conduct.

Some indication as to how to deal with this situation may come from cases concerning drugs used for therapy or routine prophylaxis. In particular, questions have been raised about the neuropsychiatric side effects of mefloquine (Lariam ${ }^{\circledR}$ ), a drug used for malaria prevention. These side effects can include

\footnotetext{
${ }^{70}$ Commonwealth Criminal Code 1995 (Cth) s 8.5 (Austl.)

${ }^{71}$ Model Penal Code § 2.08(4).

${ }^{72}$ Crimes Act 1900 (NSW) s 428A (definition of 'self-induced intoxication').

${ }^{73}$ Model Penal Code $§ 2.08(5)(b)$.
} 
sudden serious mental problems, such as paranoia and hallucinations. ${ }^{74}$ At the time of writing, a former U.S. Army staff sergeant, who in 2013 pleaded guilty to having killing 16 civilians while deployed in Afghanistan, was seeking a new trial on the basis of evidence relating to "mefloquine toxicity." 75

Other enhancements can lead to different conundrums when it comes to accountability. For example, if a warfighter, using BMI to control a weapon, launches an attack agains a civilian, how would the actus reus element of the offence be satisfied? ${ }^{76}$ After all, simply thinking about committing a crime is not punishable, even though that would have been all that the BMI-enhanced perpetrator did.

\section{B. Protection of Medical Personnel}

Enhancement has legal implications not only for the person being enhanced but potentially also for the person carrying out the enhancement. The safe administration of certain enhancements requires the involvement of medical professionals. The use of central nervous system stimulants as fatigue countermeasures is a case in point. Some of the drugs involved, such as amphetamines, are highly addictive, whereas other might have serious side effects and interact with other drugs. The implantation of medical devices would require at least minor surgery. Hence, medical practitioners often need to participate in enhancement.

Medical personnel are entitled to respect and protection under LOAC. Importantly, not every medically qualified person, or every person engaged in some medical practice, qualifies as medical personnel for LOAC purposes. Rather, one is dealing with a category of persons who have been granted special protection under LOAC by means of some formal process, and whose continued enjoyment of this protection is conditional on their exclusive assignment to certain protected medical functions. ${ }^{77}$

LOAC does not expressly specify when medical personnel lose their protection. That this can happen is generally accepted based on an analogy with the rules dealing with medical units. Medical units lose protection when used to commit,

\footnotetext{
${ }^{74}$ Roche, Medication Guide: Lariam (mefloquine hydrochloride) tablets, http://www.fda.gov/downloads/Drugs/DrugSafety/ucmo88616.pdf.

${ }^{75}$ See, e.g., Patricia Kime, Results of Scientific Inquiry into Malaria Drugs Used by US Troops Expected in March, ARMY TIMES, January 27, 2020, www.militarytimes.com/news/pentagoncongress/2019/12/26/results-of-scientific-inquiry-into-malaria-drugs-used-by-us-troopsexpected-in-march.

${ }^{76}$ See Stephen E White, Brave New World: Neurowarfare and the Limits of International Humanitarian Law, 41 CORNELL INT'L L.J. 177 (2008).

${ }^{77}$ See, in particular, Geneva Convention I, supra note 45, art. 24; Additional Protocol I, supra note 39, art. 8(c).
} 
"outside their humanitarian duties, acts harmful to the enemy." 78 If one accepts the majority view that acts harmful to the enemy need not reach the level of direct participation in hostilities in order for special protection to be lost, ${ }^{79}$ there arises a question as to what activities exactly result in the loss of such protection. The most obvious examples relate to medical personnel acting clearly outside of their medical roles, for example by providing weapons training to members of the armed forces. But, as I have argued more fully elsewhere, ${ }^{80}$ acts harmful to the enemy may well include biomedical activities going beyond the medical function of treating the wounded and sick. In particular, carrying out human enhancement procedures would constitute harmful acts, arguably resulting in a loss of protection.

\section{Conclusion}

LOAC does expressly regulate human enhancement. With respect to some enhancements, restrictions may be imposed by the rules concerning weapons, means and methods of warfare. The most general limitation seems to arise, however, from Common Article 1 of the Geneva Conventions, prohibiting the use of enhancements that diminish the ability of the warfighter to comply with LOAC.

These restrictions would be identified if a comprehensive review under Article 36 of Additional Protocol I was undertaken. However, such a review would not necessarily reveal the full range of legal consequences that the use of the enhancement would have. Human enhancement techniques therefore seem to be a scientific and technological innovation that a review contemplated by Article 36 would not fully capture. This suggests that either a rethink of these reviews would be necessary as far as enhancement is concerned, or that careful post-review legal analyses would have to be carried out to examine a broader range of legal implications.

\footnotetext{
${ }^{78}$ Geneva Convention I, supra note 45, art. 21; Geneva Convention II, supra note 45, art. 34; Additional Protocol I, supra note 39, art. 13.

${ }^{79}$ Michael Bothe, Karl Josef Partsch \& Waldemar A. Solf, New Rules for Victims of Armed Conflicts: Commentary on the Two 1977 Protocols Additional to the Geneva Conventions of 1949411 (1982);

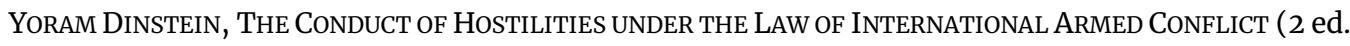
2010); Stuart Casey-Maslen, The Status, Rights, and Obligations of Medical and Religious Personnel, in The 1949 Geneva Conventions: A Commentary 807, 816 (Andrew Clapham, Paola Gaeta, \& Marco Sassòli eds., 2015); Tom Haeck, Loss of Protection, in THE 1949 GENEVA CONVENTIONS: A CoMmENTARY 839-854, 842 (Andrew Clapham, Paola Gaeta, \& Marco Sassòli eds., 2015); Bruno Demeyere, Article 24: Protection of Permanent Personnel, in CommentaRy on the First GENEVA Convention: Convention (I) FOR THE AMELIORATION OF THE CONDITION OF THE WOUNDED AND SiCK IN ARMED FoRCES IN THE FiELD 692, II 2003 (Knut Dörmann et al. eds., 2nd ed. 2016).

${ }^{80}$ Rain Liivoja, Biomedical Enhancement of Warfighters and the Legal Protection of Military Medical Personnel in Armed Conflict, 26 MED. L. REV. 421 (2018).
} 